\title{
Assessment of clinical effects and safety of an oral supplement based on marine protein, vitamin C, grape seed extract, zinc, and tomato extract in the improvement of visible signs of skin aging in men
}

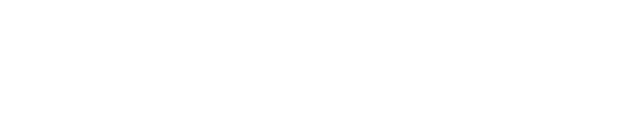

Adilson Costa',2
Elisangela Samartin Pegas
Pereira'
Elvira Cancio Assumpção'
Felipe Borba Calixto dos
Santos'
Fernanda Sayuri Ota'
Margareth de Oliveira
Pereira'
Maria Carolina Fidelis'
Raquel Fávaro'
Stephanie Selma Barros
Langen'
Lúcia Helena Favaro de
Arruda'
Eva Nydal Abildgaard'3
'Department of Dermatology,
Pontifícia Universidade Católica de
Campinas, Campinas, São Paulo, Brazil;
'KOLderma Clinical Trials Institute,
Campinas, São Paulo, Brazil; ${ }^{3 P f i z e r}$
Consumer Healthcare, Nutritional
Sciences, Copenhagen, Denmark

Adilson Costa ${ }^{1,2}$

Elisangela Samartin Pegas

Pereira

Elvira Cancio Assumpção

Felipe Borba Calixto dos

Santos

Margareth de Oliveira

Pereira

Maria Carolina Fidelis

Stephanie Selma Barros

Langen

Lúcia Helena Favaro de

Arruda

'Department of Dermatology,

Sciences, Copenhagen, Denmark

Correspondence: Adilson Costa

Rua Original, 219, 05435-050,

Vila Madalena, São Paulo, Brazil

Tel +55 II 3034 I I 70

Fax +55 I| 3034 |932

Email adilson_costa@hotmail.com
Background: Skin aging is a natural process that may be aggravated by environmental factors. Topical products are the conventional means to combat aging; however, the use of oral supplements is on the rise to assist in the management of aged skin.

Objective: The purpose of this study was to assess the effects and safety of an oral supplement containing (per tablet) marine protein $(105 \mathrm{mg})$, vitamin C (27 mg), grape seed extract (13.75 mg), zinc $(2 \mathrm{mg})$, and tomato extract $(14.38 \mathrm{mg}$ ) in the improvement of skin aging in men.

Methods: This single-center, open-label, quasi-experimental clinical study enrolled 47 male subjects, aged 30-45 years, with phototypes I-IV on the Fitzpatrick scale. Subjects received two tablets of the oral supplement for 180 consecutive days. Each subject served as their own control. Clinical assessments were made by medical personnel and by the subjects, respectively. Objective assessments were carried out through $\mathrm{pH}$ measurements, sebumetry, corneometry, ultrasound scanning, skin biopsies, and photographic images.

Results: Forty-one subjects ( $87 \%$ ) completed the study. Clinical improvements on both investigator- and subject-rated outcomes were found for the following parameters: erythema, hydration, radiance, and overall appearance $(P<0.05)$. The objective measurements in the facial skin showed significant improvements from baseline in skin hydration $(P<0.05)$, dermal ultrasound density $(P<0.001)$, and reduction of skin $\mathrm{pH}(P<0.05)$. No statistical improvement in relation to sebum was found. The photographic assessment showed an improvement in the overall appearance. The results of the objective measurements were found to be correlated with the subjects' satisfaction by an increase of collagen and elastic fibers.

Conclusion: The use of an oral supplement based on a unique biomarine complex, vitamin $\mathrm{C}$, grape seed extract, zinc, and tomato extract produced improvements in the signs of skin aging in men.

Keywords: supplements, antioxidants, skin hydration, dermal density

\section{Introduction}

Increased life expectancy is one of the greatest global public health challenges. In Brazil, the number of adults aged 60 years or older will reach an estimated 32 million in 2020. Parallel to changes in the age pyramid, age-related challenges arise, and interest in combating visible signs of skin aging increases.

Skin aging is a gradual, natural process divided into intrinsic and extrinsic aging, involving genetic, hormonal, and environmental mechanisms. Intrinsic aging, also called chronological aging, may be influenced by exogenous factors, such as smoking, alcohol consumption, and exposure to ultraviolet (UV) radiation, thus characterizing 
extrinsic aging. Free radicals play an essential role in both processes. $^{2-5}$

Generation of free radicals is a physiological process, performing essential biological functions in various biochemical reactions, such as generation of ATP and participation in defense mechanisms during an infectious process. ${ }^{5}$ However, formation of free radicals in vivo also occurs due to exposure to external factors, such as smoking, medicines, and UV radiations. ${ }^{6}$ Arising from an aerobic metabolism, oxygen $\left(\mathrm{O}_{2}\right)$ undergoes a tetravalent reduction, generally in mitochondria, receiving four electrons, resulting in the formation of water molecules $\left(\mathrm{H}_{2} \mathrm{O}\right)$. Reactive intermediaries are formed, such as hydrogen peroxide $\left(\mathrm{H}_{2} \mathrm{O}_{2}\right)$, superoxide $\left(\mathrm{O}_{2}^{-}\right)$, hydroperoxyl $\left(\mathrm{HO}_{2}\right)$, and hydroxyl $(\mathrm{OH}) .^{7}$

Free radicals and other active oxygen derivatives are inevitably coproduced in the metabolic process; if their production is excessive and prolonged, they may be involved in various deleterious processes. ${ }^{8}$ Formation of free radicals, which are highly reactive molecules, is a widely accepted mechanism in skin aging and involves direct harm to various cellular structures such as lipids, proteins, and DNA. ${ }^{9}$ Production of free radicals increases with age, while endogenous defense mechanisms decrease. This unbalance leads to progressive deterioration of cellular structures, resulting in accelerated aging. ${ }^{2}$

UV irradiation is the largest contributor to extrinsic aging. In skin, UV penetration depends on its wave length, and UVB radiation reaches the epidermis and a small part of the upper dermis, affecting keratinocytes. UVA quickly reaches the dermis, including its deeper layers, compromising local fibroblasts. ${ }^{2,10}$ Due to its ability to deeply penetrate the dermis, it is believed that UVA, in particular, plays an important role in photoaging. ${ }^{10}$

Dermal histopathological changes observed in photodamaged skin are represented by decrease of collagen ${ }^{11}$ and its precursors, ${ }^{11,12}$ in addition to replacement of elastic fibers by an amorphous material., ${ }^{2,12}$ Inflammation as a result of photodamage leads to proliferation of lymphocytes, mastocytes, and macrophages, in addition to an increase of capillary fragility. ${ }^{12}$ Chronically sun-exposed skin presents a thickening of the stratum corneum, with acanthotic epidermis and dysplasia with cellular atypia and anaplasia., ${ }^{2,13}$ Keratinocytes become irregular with loss of polarity and disordered melanocytes. ${ }^{2,13}$

There is a great variety of dietary antioxidant substances, which can be classified into intra- or extracellular substances dependent on their origin and/or location. ${ }^{14}$ Zinc is a mineral with antioxidative properties; it is involved in stimulus of synthesis of metallothionein (low-molecular-weight protein with antioxidant properties) in the structure of dismutase superoxide enzyme, which catalyzes the conversion of two superoxide ion radicals to $\mathrm{H}_{2}$ and $\mathrm{O}_{2}$ peroxide, transforming a highly reactive species (superoxide ion) into a less aggressive form $\left(\mathrm{H}_{2}\right.$ peroxide). Furthermore, it protects sulfhydryl groups of cell membrane proteins by antagonism with prooxidant metals such as iron and copper. ${ }^{14}$ It also has a role in the stability of cellular membranes when it promotes the association between membrane proteins and cytoskeletons. $^{14}$

Tomatoes and their derivatives are considered main sources of lycopene, a liposoluble carotenoid that has a huge ability to scavenge singlet oxygen, promoting an antioxidant activity in lipidic phases by blocking free radicals that harm lipoprotein membranes, in addition to being an efficient inhibitor of cellular proliferation. ${ }^{15}$ Carotenoids also modulate carcinogenic metabolism, stimulate cellular communication (gap junctions), and increase immune response. ${ }^{15}$ Studies show that lycopene protects lipids, low-density lipoproteins, proteins, and DNA from the attack of radicals, playing an essential role in protection from diseases. ${ }^{15}$ These studies suggest that lycopene contributes to UV protection in human skin, confirming that oral carotene supplementation provides moderate protection from UV-induced erythema. ${ }^{16,17}$

A known antioxidant is ascorbic acid (vitamin $\mathrm{C}$ ), which is found in fruits such as acerola, orange, lemon, and tangerine, and in crude vegetable leaves and tomato. ${ }^{18}$ As the human organism is unable to synthetize this substance due to absence of the hepatic enzyme L-gulonolactoneoxidase, human beings need to obtain it through diet, and it is considered an important supplement. ${ }^{18}$ Vitamin C stimulates collagen synthesis, acting as a cofactor in reactions of hydroxylation of proline and lysine, which are essential amino acids in the formation of collagen fibers. ${ }^{18}$ It participates in the integrity of connective tissue, cartilage, osseous matrix, tendons, and skin, besides being involved in the cicatricial process. ${ }^{18,19}$ It also has an anti-inflammatory effect and important antioxidant action, preventing formation of free radicals. ${ }^{18-20}$

Another fruit with high antioxidant capacity and a great source of phenolic compounds is grape. ${ }^{21}$ Components of grape seed and peel, flavonoids (proanthocyanidins), phenolic acids, and stilbenes (resveratrol) have a functional activity. ${ }^{21-23}$ Proanthocyanidin extract originated from the seed has an important antioxidant activity, preventing tissue oxidative damages by reducing lipidic oxidation and/or inhibiting free radical production. ${ }^{22,23}$ 
Studies show that substances rich in proteins and polysaccharides from marine origin efficiently postpone skin aging with significant structural changes, and these are part of the set of antioxidant supplements available on the market. ${ }^{24,25}$ Clinical studies of a food supplement of marine origin rich in proteins and polysaccharides have found it improves photoaged skin. This has been demonstrated by improvements in parameters of photoaging, improved clinical gradings, increased dermal density, and increased skin moisture content. ${ }^{24,25}$ An in vitro study suggests that deposit of collagen fibers in the dermis is one possible mean of action. ${ }^{26}$

\section{Materials and methods}

The trial was conducted as an open-label, single-center, quasi-experimental study, approved by the Ethic Committee, complying with Good Clinical Practices in Human Beings, involving 47 male subjects between 30 and 45 years old, phototypes I-IV on the Fitzpatrick scale, free of diseases that could interfere in skin aging assessment, and without a history of allergy to the products under testing nor to seafood, besides not being smokers or illicit-drug users.

Subjects presented with intact skin in the region under assessment, refrained from sun exposure in an intense manner, and did not use immunosuppressors or other drugs and topic retinoic derivatives on the face and/or upper limbs within 60 pretrial days. Use of oral isotretinoin within the last 360 days prior to the study beginning was also prohibited.

After having read, understood, agreed to, and signed the Free and Clarified Consent form, subjects made exclusive use of facial photoprotector Episol lotion SPF15 (Mantecorp Indústria Química e Farmacêutica Ltda, Rio de Janeiro, Brazil) twice a day starting on day 1 for $\geq 30$ consecutive days before initiating treatment and throughout the study. Subjects were prohibited from using other cosmetics, supplements, or any treatment used for photoaging that could interfere with treatment or assessment of results. After this washout phase, subjects started daily use of two tablets of Imedeen Man.Age. Ment (Ferrosan Laboratórios S/A, Copenhagen, Denmark) (54 $\mathrm{mg}$ of vitamin $\mathrm{C}$ [L-ascorbic acid]; $28.76 \mathrm{mg}$ tomato extract, providing lycopene; $27.5 \mathrm{mg}$ of grape seed extract, providing proanthocyanidins; $210 \mathrm{mg}$ of marine complex, composed of fish proteins and polysaccharides; $4 \mathrm{mg}$ of zinc gluconate) orally, in a single intake, for 180 consecutive days.

Subjects made eight monthly visits to the clinic. At all post-baseline visits, subjects underwent assessments in facial skin (left preauricular region, photoexposed area) and in the inner region of the left arm (photoprotected area) including corneometry, sebumetry, and pHmetry (Derma Unit SSC3; Courage + Khazaka Electronic, Köln, Germany) for evaluation of hydration (expressed in hydration units), sebum (expressed in $\mathrm{mg} / \mathrm{cm}^{2}$ ), and skin $\mathrm{pH}$, respectively. Skin ultrasound scanning (Derma Scan; Cortex Technology, Hadsund, Denmark) to determine dermal density (measured in pixels and expressed as arbitrary units) and digital facial photography were also conducted. Facial photographs were taken of the frontal incidence, $45^{\circ}$ to the right and $45^{\circ}$ to the left, in a blackout room using the VISIA skin complex analysis system (Canfield Imaging Systems, Fairfield, NJ, USA). The VISIA system provided scoring (number of distinct occurrences of the characteristic), grading (impact of the characteristic on subjects' skin [size, total area, and intensity]), and/or percentile of improvement (based on an initial assessment of subjects' skin compared with persons of the same age, sex, and skin type) for the following characteristics:

- Spots: brown/red lesions (eg, freckles, acne scars, hyperpigmentation, vascular injuries) distinguished by their color/contrast with skin tone; varying size; generally circular shape.

- UV spots: subsurface spots caused by accumulation of melanin under the skin from sun damage; generally invisible under normal lighting; detectable by VISIA under UV light.

- Brown spots: lesions such as hyperpigmentation, freckles, liver spots, and melasma caused by excess melanin; produce an irregular skin appearance; detected in VISIA by RBX Technology (Canfield Imaging Systems).

- Red areas: variety of conditions (eg, acne, inflammation, rosacea, vessels) with red color, which is detected using VISIA by RBX Technology.

- Wrinkles: furrows, folds, or creases in skin that increase with sun exposure; identified by characteristic long, narrow shape.

- Texture: skin color and smoothness; measured by identifying gradations in color from surrounding skin tone, as well as peaks and valleys on skin surface indicating variations in surface texture.

- Pores: circular surface openings of sudoriferous gland ducts; identified by dark color and circular shape; distinguished from spots based on size.

- Porphyrins: bacterial excretions that may be present in pores and cause acne; exhibit characteristic circular white spots under UV light. 

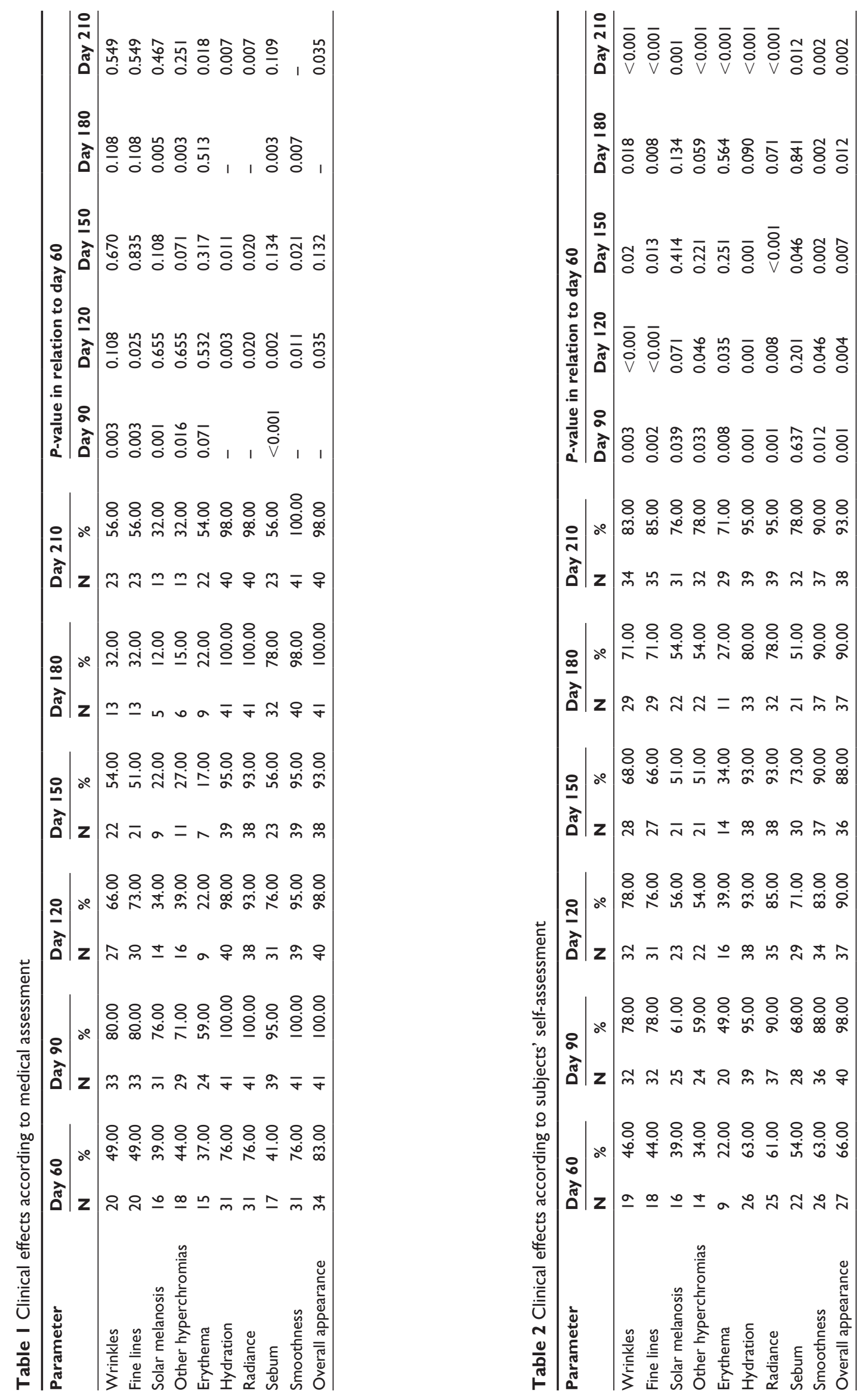
At visits made on day 30 (baseline) and day 210 (study completion), skin biopsies were carried out, with punch number 2 , in the sun-exposed area and in the photoprotected area, aiming to assess collagen and elastic fiber patterns; these structures were numerically assessed through Image-Pro software system (Image-Pro Plus 7.0.1; Media Cybernetics, Bethesda, MD, USA). From the third visit (day 60) through the final visit (day 210), physicians and subjects subjectively assessed therapeutic response. Wrinkles, fine lines, solar melanosis, other hyperchromias, erythema, hydration, radiance, sebum, smoothness, and overall appearance were assessed. Investigators and subjects assessed tolerability (safety) in relation to adverse events (AEs) throughout the study. The potential relationship of these AEs to the study supplement was determined by the study investigator.

Therapeutic response to supplementation (at that time point relative to the initial visit) was assessed according to the following scale: +4 (100\% improvement without skin aging), +3 (accented improvement: 50\%-99\%), +2 (moderate improvement: $25 \%-50 \%$ ), +1 (discrete improvement: $\leq 25 \%$ ), 0 (maintained), -1 (discrete worsening: $\leq 25 \%$ ), -2 (moderate worsening: $25 \%-50 \%),-3$ (worsening: $50 \%-99 \%$ ), and -4 (100\% worsening in skin aging). To compare changes over time, a homogeneity test was used for categorical variables and a Wilcoxon test was used for continuous variables using SPSS version 16.0 software (SPSS Inc., Chicago, IL, USA). In all analyses, the level of significance was $P<0.05$.

\section{Results}

Of the initial 47 subjects, 41 (87\%) completed the study. Subjects' average age was 39.1 years, and $68.3 \%$ were phototype III (12.2\% were phototype II, $19.5 \%$ phototype IV) in accordance with Fitzpatrick classification.

Upon medical assessment, significant improvements were observed at study end in the following outcomes: erythema, hydration, radiance, and overall appearance $(P<0.05$ for all). Results of the subjects' assessment at study end showed a significant level of improvement in all assessed parameters $(P<0.05)$. The highest degree of improvement occurred within 60 days of product use; there was no report of "worsening" at any time during the study (Table 1). According to the subjects' evaluation, the highest degree of improvement occurred at distinct moments for different outcomes: day 90 (hydration and overall appearance), day 150 (smoothness), and day 210 (wrinkles, fine lines, solar melanosis, erythema, radiance, and sebum) (Table 2 ).

Photographic assessment showed a decrease in intensity of tone of general skin spots, UV spots, and brown spots associated with improvement of skin texture and appearance of pores; these improvements remained statistically significant (Table 3).

There was an increase of 8.3 hydration units in facial skin hydration (corneometry; $P=0.014)$ and a decrease of 0.2 in facial skin $\mathrm{pH}(P<0.001)$ (Table 4). An increase in facial dermal ultrasound density of 38.4 arbitrary units was observed $(P<0.001)$. There was no statistical difference over 7 months in relation to sebumetry (face: $2.9 \mathrm{mg} / \mathrm{cm}^{2}$ $[P=0.861]$; arm: $\left.0.1 \mathrm{mg} / \mathrm{cm}^{2}[P=0.398]\right)$, demonstrating that the product is not sebogenic.

Biopsy results revealed a significant increase in percentage of collagen $(43 \%-57 \% ; P<0.001)$ and elastic fibers $(20 \%-31 \% ; P<0.001)$ in the face (photoexposed area).

Table 3 Grading (arbitrary units) and percentile improvement in the objective clinical parameters according to the VISIA system at day 210 in relation to day 30

\begin{tabular}{|c|c|c|c|c|c|}
\hline & Day 30 & Day 210 & Improvement & $\%$ improvement & $P$-value \\
\hline \multicolumn{6}{|l|}{ Spots } \\
\hline Grading & 2,665 & 2,453 & 212 & 8 & 0.008 \\
\hline Percentile & $47 \%$ & $57 \%$ & $10 \%$ & 21 & $<0.001$ \\
\hline \multicolumn{6}{|l|}{ Texture } \\
\hline Grading & 2,403 & 2,090 & 313 & 34 & 0.017 \\
\hline Percentile & $58 \%$ & $69 \%$ & $11 \%$ & 19 & 0.001 \\
\hline \multicolumn{6}{|l|}{ Pores } \\
\hline Grading & 2,334 & 1,896 & 438 & 23 & 0.001 \\
\hline Percentile & $44 \%$ & $65 \%$ & $21 \%$ & 48 & $<0.001$ \\
\hline \multicolumn{6}{|l|}{ UV spots } \\
\hline Grading & $\mathrm{I}, 057$ & 599 & 458 & 76 & $<0.001$ \\
\hline \multicolumn{6}{|l|}{ Brown spots } \\
\hline Grading & 5,418 & 3,539 & $\mathrm{I}, 879$ & 53 & $<0.001$ \\
\hline
\end{tabular}

Note: aCanfield Imaging Systems, Fairfield, NJ, USA.

Abbreviation: UV, ultraviolet. 
Table 4 Changes in facial skin hydration, facial skin pH, facial density, facial sebumetry, and sebumetry of inner side of arm (arm sebumetry) during the study

\begin{tabular}{|c|c|c|c|c|c|c|}
\hline & Average & Median & Standard deviation & Minimum & Maximum & $P$-value \\
\hline \multicolumn{7}{|c|}{ Face corneometry (hydration units) } \\
\hline Day 30 & 59.3 & 54.4 & 18.9 & 39.2 & 162.4 & 0.014 \\
\hline Day 210 & 67.6 & 63.0 & 21.0 & 34.4 & 113.4 & \\
\hline \multicolumn{7}{|c|}{ Face pHmetry } \\
\hline Day 30 & 4.8 & 4.8 & 0.5 & 3.5 & 6.0 & $<0.001$ \\
\hline Day 210 & 4.6 & 4.6 & 0.4 & 3.5 & 5.2 & \\
\hline \multicolumn{7}{|c|}{ Ultrasound scan, face (arbitrary units) } \\
\hline Day 30 & 31.41 & 29 & 7.5 & 18 & 50 & $<0.001$ \\
\hline Day 210 & 69.77 & 66 & 10.32 & 55 & 96 & \\
\hline \multicolumn{7}{|c|}{ Face sebumetry $\left(\mathrm{mg} / \mathrm{cm}^{2}\right)$} \\
\hline Day 30 & 98.0 & 86.3 & 50.5 & 22.0 & 218.8 & 0.861 \\
\hline Day 210 & 100.9 & 85.7 & 54.1 & 18.0 & 254.0 & \\
\hline \multicolumn{7}{|c|}{ Arm sebumetry $\left(\mathrm{mg} / \mathrm{cm}^{2}\right)$} \\
\hline Day 30 & 7.0 & 1.0 & 16.2 & 0.0 & 78.0 & 0.398 \\
\hline Day 210 & 7.1 & 2.0 & 13.0 & 0.0 & 71.0 & \\
\hline
\end{tabular}
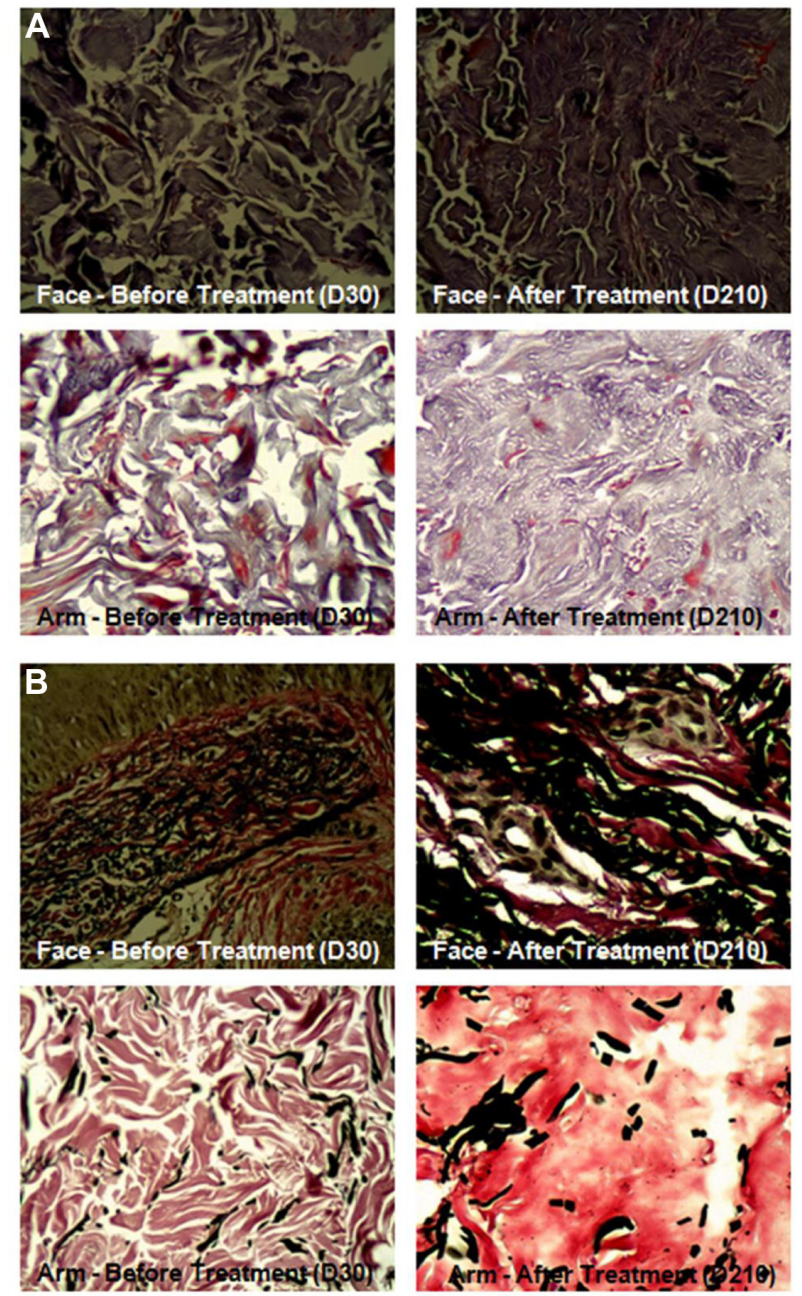

Figure I Histological images showing collagen and elastic fibers of face and left arm before and after treatment.

Notes: (A) Collagen evidenced by Masson's trichrome method. (B) Elastic fibers evidenced by Verhoeff method.

Abbreviation: D, day.
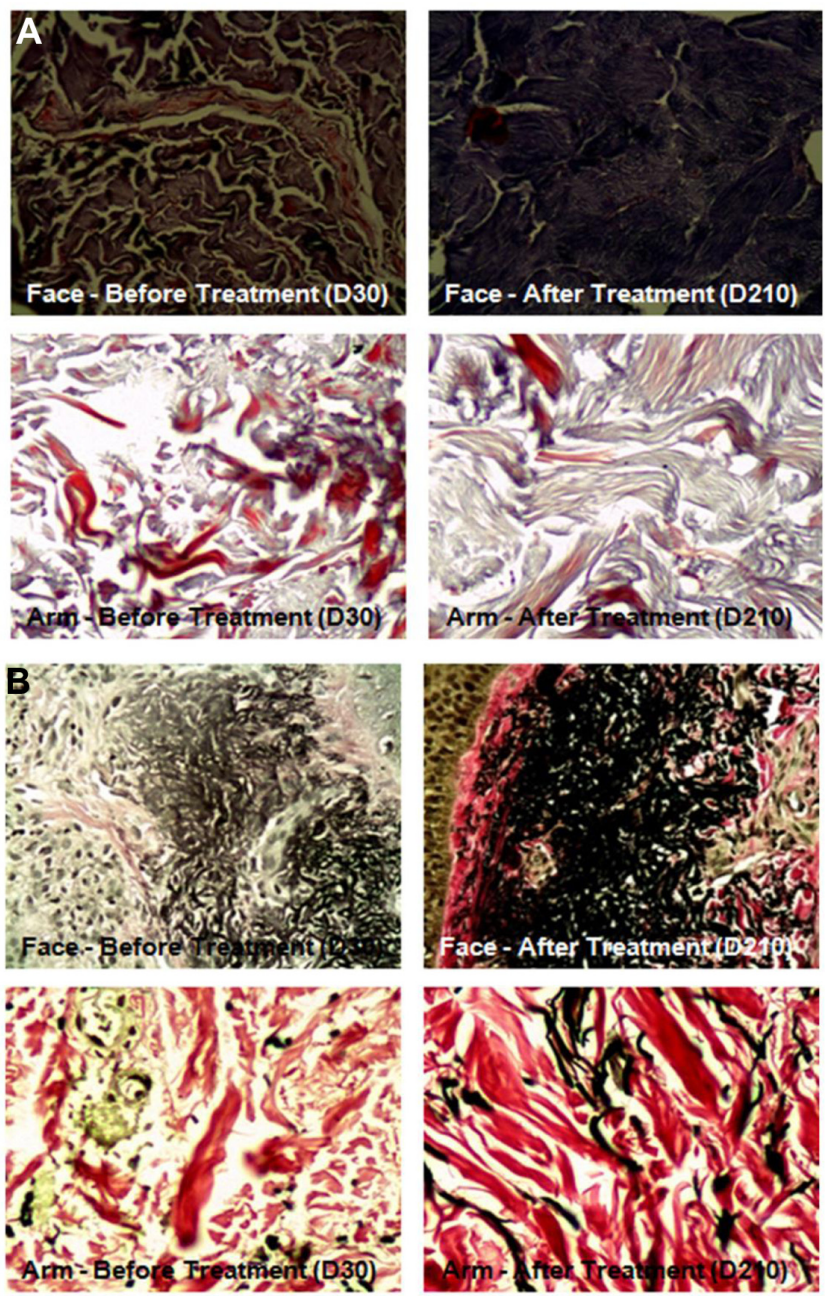

Figure 2 Histological exam showing collagen and elastic fibers of face and left arm before and after treatment.

Notes: (A) Collagen evidenced by Masson's trichrome method. (B) Elastic fibers evidenced by Verhoeff method.

Abbreviation: D, day. 
Examples of pre- and posttreatment images of collagen and elastic fibers are presented in Figures 1 and 2, respectively. In the arm (photoprotected area), there was a significant increase of collagen $(42 \%-57 \% ; P<0.001)$ and elastic fibers $(15 \%-20 \% ; P=0.004$ (Figure 3 and Table 5). Similarly, in facial skin, there was an increase of collagen $(34 \%$; $P<0.001)$ and elastic fibers $(59 \% ; P<0.001)$ (Figures 3 and Table 6).

Mild AEs that were considered by the investigator to be possibly related to the study supplement were observed in five subjects. These AEs included retching, migraine, and increased sebum $(n=1)$; spots and acne $(n=1)$; change in excrement color $(n=1)$; diarrhea $(n=1)$; and dyspepsia $(\mathrm{n}=1)$.

\section{Discussion}

Skin aging can cause psychological effects, and there has been much attention toward trying to understand the physiopathologic process behind skin aging. This has resulted in numerous antiaging therapeutics emerging. ${ }^{1}$ The process is influenced by genetic and environmental factors, and chronic sun exposure and smoking are the main factors responsible for extrinsic aging, with consequent production of free radicals that play a role in photoaged skin. ${ }^{3,4,6}$ Formation of free radicals, which are highly reactive molecules, is a mechanism involved in skin aging that directly harms various cellular structures, lipids, proteins, and DNA. ${ }^{9}$

Oxidative stress arises from excessive generation of free radicals or from retardation of the scavenging process of free radicals from the organism, culminating in oxidation of biomolecules with consequent loss of biological functions. ${ }^{5}$ Ongoing production of free radicals leads to the development of antioxidant mechanisms, divided into enzymatic and nonenzymatic systems, which inhibit and/ or reduce deleterious effects of free radicals, prevent their

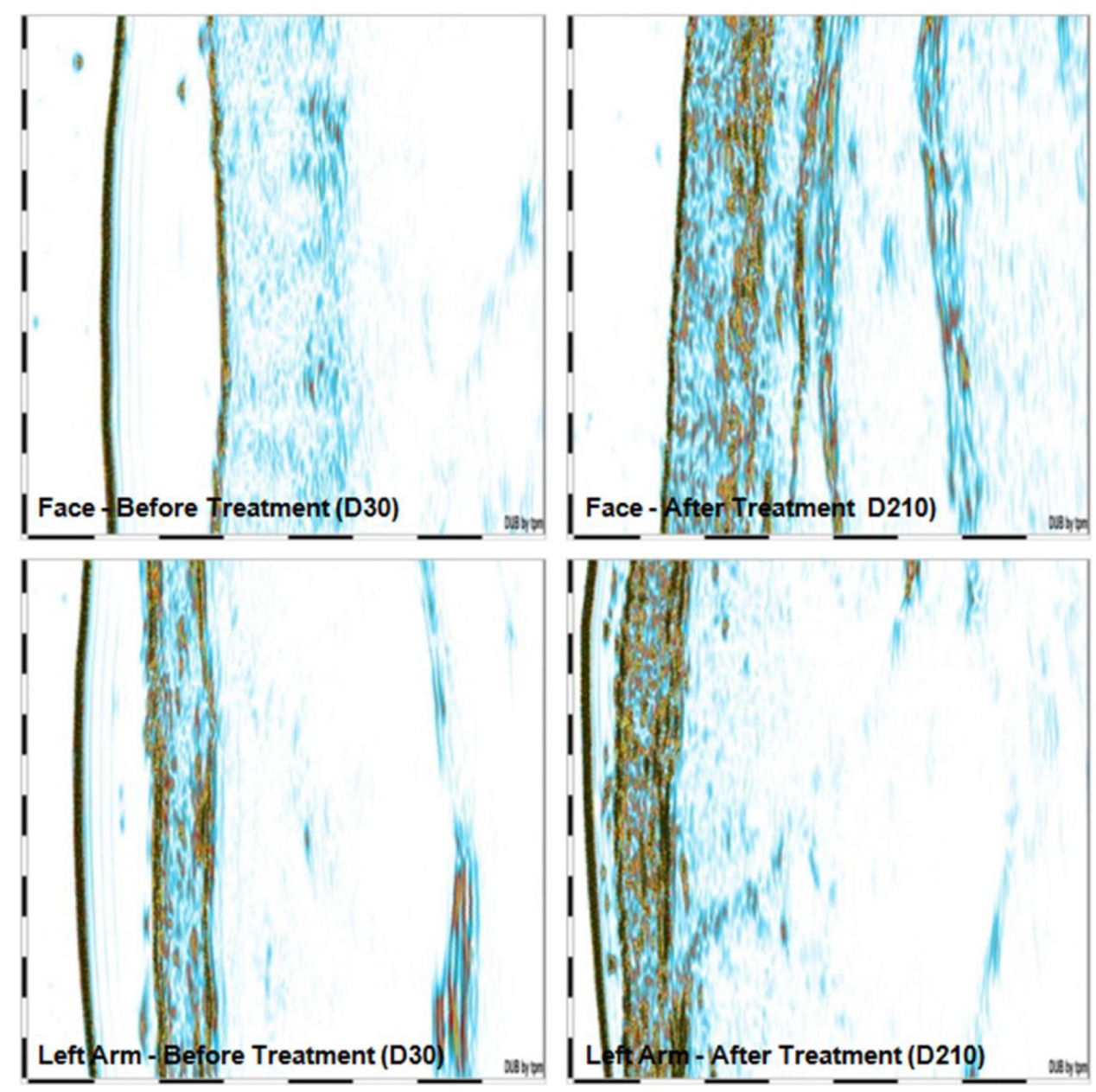

Figure 3 Collagen evidenced by ultrasound images before and after intervention. Abbreviation: D, day. 
formation and action, and reconstitute injured biological structures. $^{5}$

Since free radicals actively influence the photoaging process of skin, ${ }^{9}$ development of products aimed at fighting free radicals becomes highly relevant in minimizing skin tissue damage. Antioxidants play an essential role in preventing skin aging. ${ }^{5}$

Our study results suggest the potential positive effects of oral supplementation rich in antioxidant agents on photoaging. Dermal histopathological changes observed in photodamaged skin are reflected in the decrease of collagen ${ }^{11}$ and its precursors, in addition to the degeneration of the elastic fibers, which are replaced by an amorphous material. ${ }^{2,12}$ In this study, we found statistical increases in the percentage of collagen and elastic fibers and in face dermal ultrasound density. These results are consistent with previous studies with dietary supplements containing antioxidants and biomarine complex that also showed improvements in parameters of photoaging (both significant histological and ultrasound improvement in dermal collagen for photoexposed and photoprotected areas). ${ }^{24,25}$

Lycopene and other substances such as vitamin C, zinc, and marine proteins and polysaccharides present in the oral supplement studied have been reported as important agents in the fight against tissue inflammation, prevention of free radical formation, and free radical removal, which could have potentially positive effects on the signs of photoaging. ${ }^{14,15,18,27-29}$

In addition to its antioxidant role, vitamin $\mathrm{C}$ stimulates collagen synthesis, acting as a cofactor in the hydroxylation of proline and lysine, essential amino acids in the formation of collagen fibers. ${ }^{18}$ In this study, such ability was demonstrated through the increase of dermal density confirmed by ultrasound results, in addition to the histological increase of collagen and elastic fibers observed.

The epidermis, an external compartment of the skin, has, in the stratum corneum, a semipermeable laminar surface of keratinocytes, the most important skin portion of the physiological barrier, ${ }^{10}$ with fundamental participation in the skin hydration process ${ }^{27,28}$ and interaction with adjacent epidermal layers. ${ }^{30}$ It has an essential acid $\mathrm{pH}$ for permeability of the homeostasis barrier, a fact based on its delayed recovery when injured skin sites are sunk in neutral pH neutron surfaces. ${ }^{10}$

Acidification seems to act in barrier homeostasis through regulation of enzymes involved in extracellular processing, such as acid sphingomyelinase and $\beta$-glucocerebrosidase, whose $\mathrm{pH}$ is acid. ${ }^{10,30}$ Product deposits derived from sebaceous and sweat glands, hydrolysis of phospholipids to free fatty acids, deamination of histidine to urocanic acid, and production of protons in the stratum corneum could explain the gradient of local interstitial $\mathrm{pH}$, in addition to the selective acidification of membrane microdomains. ${ }^{10}$ Accordingly, local acidification is associated with maintenance of skin hydration. ${ }^{27}$

In accordance with the final medical and subject assessment, significant improvement in most parameters assessed (wrinkles, fine lines, solar melanosis, erythema, hydration, radiance, smoothness, sebum, and overall appearance) was noted, confirmed by histological, ultrasound, and instrumental findings.

Although this study contributes relevant data to the literature by assessing an oral dietary supplement for treating photoaged skin in an exclusively male population, some limitations in the study design will require additional, more stringently designed clinical trials to establish efficacy in males. The lack of a comparator group limits the conclusions that can be drawn about the effectiveness of this product. Furthermore, the relatively small population size, lack of power calculations, and justification for the sample size also limit generalizability of these results.

\section{Conclusion}

Analysis of clinical data suggests that daily oral supplementation based on a unique marine complex, vitamin $\mathrm{C}$, grape seed extract, zinc, and tomato extract has some beneficial effects on clinical parameters of skin photoaging in men. Improvement in dermal density and facial skin hydration, associated with reduction of local $\mathrm{pH}$ and increase of collagen and elastic fibers, suggests potential positive effects of this

Table 5 Evolution of collagen and elastic fibers of inner side of left arm long the study according to histological findings

\begin{tabular}{|c|c|c|c|c|c|c|}
\hline Left arm biopsy & Average (\%) & Median (\%) & Standard deviation (\%) & Minimum (\%) & Maximum (\%) & $P$-value \\
\hline \multicolumn{7}{|l|}{ Collagen } \\
\hline Day 30 & 42.5 & 42.9 & $1 \mathrm{I} .4$ & 10.2 & 62.4 & $<0.001$ \\
\hline Day 210 & 57.4 & 58.2 & 9.6 & 39.5 & 76.6 & \\
\hline \multicolumn{7}{|l|}{ Elastic fibers } \\
\hline Day 30 & 14.6 & 12.8 & 7.9 & 4.4 & 33.7 & 0.004 \\
\hline Day 210 & 19.8 & 18.1 & 9.3 & 7.4 & 51.8 & \\
\hline
\end{tabular}


Table 6 Evolution of facial collagen and elastic fibers during the study according to histological findings

\begin{tabular}{lllllll}
\hline Face biopsy & Average (\%) & Median (\%) & Standard deviation (\%) & Minimum (\%) & Maximum (\%) & P-value \\
\hline Collagen & & & & & & \\
$\quad$ Day 30 & 43.0 & 42.5 & 9.9 & 25.2 & 66.0 & 89.6 \\
Day 210 & 57.4 & 57.8 & 9.7 & & & \\
Elastic fibers & & 16.6 & 13.3 & 4.6 & 58.8 & \\
Day 30 & 19.7 & 16.0 & 9.3 & 64.8 \\
Day 210 & 31.2 & 26.9 & 16.0 & 0.001 \\
\hline
\end{tabular}

product for skin aging. This oral supplementation was shown to be safe in this population of mostly middle-aged men.

\section{Acknowledgments}

The support provided by Carla Resvanis of Peloton Advantage, LLC, was funded by Pfizer and consisted only of manuscript formatting; no contribution was made to the editorial content.

\section{Disclosure}

This study was sponsored by Ferrosan Laboratórios Ltda., São Paulo, SP, Brazil, which was acquired by Pfizer in December 2011. This publication includes data that precede Pfizer's involvement when it comes to validation. The authors report no other conflicts of interest in this work.

\section{References}

1. Lima-Costa MF, Veras R. Saúde pública e envelhecimento. [Public health and aging] Cad Saude Publica. 2003;19(3):700-701. Portuguese.

2. Bogdan Allemann I, Baumann L. Antioxidants used in skin care formulations. Skin Therapy Lett. 2008;13(7):5-9.

3. Landau M. Exogenous factors in skin aging. Curr Probl Dermatol. 2007;35:1-13.

4. Naylor EC, Watson RE, Sherratt MJ. Molecular aspects of skin ageing. Maturitas. 2011;69(3):249-256.

5. Barbosa KBF, Costa NMB, Alfenas RCG, De Paula SO, Minim VPR, Bressan J. Estresse oxidativo: conceito, implicações e fatores modulatórios. [Oxidative stress: concept, implications and modulating factors] Revista de Nutrição. 2010;23:629-643. Portuguese.

6. Bianchi MLP, Antunes LMG. Radicais livres e os principais antioxidantes da dieta. [Free radicals and the main dietary antioxidants] Revista de Nutrição. 1999;12:123-130. Portuguese.

7. Ferreira ALA, Matsubara LS. Radicais livres: conceitos, doenças relacionadas, sistema de defesa e estresse oxidativo. [Free radicals: concepts, related diseases, defense system and oxidative stress] Rev Assoc Med Bras. 1997;43:61-68. Portuguese.

8. Rocha FD, Pereira RC, Kaplan MAC, Teixeira VL. Produtos naturais de algas marinhas e seu potencial antioxidante. [Natural products from marine seaweeds and their antioxidant potential] Rev Bras Farmacogn. 2007;17:631-639. Portuguese.

9. Svobodova A, Walterova D, Vostalova J. Ultraviolet light induced alteration to the skin. Biomed Pap Med Fac Univ Palacky Olomouc Czech Repub. 2006;150(1):25-38.

10. Runger MT. Radiação Ultravioleta. [Ultraviolet Radiation]. Dermatologia. 2011:1321-1331. Portuguese.

11. Talwar HS, Griffiths CE, Fisher GJ, Hamilton TA, Voorhees JJ. Reduced type I and type III procollagens in photodamaged adult human skin. J Invest Dermatol. 1995;105(2):285-290.
12. Quan T, He T, Kang S, Voorhees JJ, Fisher GJ. Solar ultraviolet irradiation reduces collagen in photoaged human skin by blocking transforming growth factor-beta type II receptor/Smad signaling. Am J Pathol. 2004;165(3):741-751.

13. Montagner S, Costa A. Bases biomoleculares do fotoenvelhecimento [Molecular basis of photoaging]. An Bras Dermatol. 2009;84(3):263269. Portuguese.

14. Koury JC, Donangelo CM. Zinco, estresse oxidativo e atividade física. [Zinc, oxidative stress and physical activity] Revista de Nutrição. 2003;16:433-441. Portuguese.

15. Shami NJIE, Moreira EAM. Licopeno como agente antioxidante. [Lycopene as an antioxidant agent] Revista de Nutrição. 2004;17:227-236. Portuguese.

16. Liu C, Lian F, Smith DE, Russell RM, Wang XD. Lycopene supplementation inhibits lung squamous metaplasia and induces apoptosis via up-regulating insulin-like growth factor-binding protein 3 in cigarette smoke-exposed ferrets. Cancer Res. 2003;63(12): $3138-3144$.

17. Aust O, Stahl W, Sies H, Tronnier H, Heinrich U. Supplementation with tomato-based products increases lycopene, phytofluene, and phytoene levels in human serum and protects against UV-light-induced erythema. Int J Vitam Nutr Res. 2005;75(1):54-60.

18. Aranha FQ, Barros ZF, Moura LSA, et al. O papel da vitamina C sobre as alterações orgânicas no idoso. [The role of vitamin c in organic changes in aged people] Revista de Nutrição. 2000;13:89-97. Portuguese.

19. Petroianu A, Alberti LR. Effect of oral supplementation of vitamin $C$ on intestinal anastomotic resistance. Rev Col Bras Cir. 2011;38(1):54-58. English, Portuguese.

20. Panich U, Tangsupa-a-nan V, Onkoksoong T, et al. Inhibition of UVAmediated melanogenesis by ascorbic acid through modulation of antioxidant defense and nitric oxide system. Arch Pharm Res. 2011;34(5): 811-820.

21. Nemen D, Lemos-Senna E. Preparação e caracterização de suspensões coloidais de nanocarreadores lipídicos contendo Resveratrol destinados à administração cutânea. [Preparation and characterization of resveratrol-loaded lipid-based nanocarriers for cutaneous administration] Quim Nova. 2011;34:408-413. Portuguese.

22. Sato M, Bagchi D, Tosaki A, Das DK. Grape seed proanthocyanidin reduces cardiomyocyte apoptosis by inhibiting ischemia/reperfusioninduced activation of JNK-1 and C-JUN. Free Radic Biol Med. 2001; 31(6):729-737.

23. Jia Z, Song Z, Zhao Y, Wang X, Liu P. Grape seed proanthocyanidin extract protects human lens epithelial cells from oxidative stress via reducing NF-אB and MAPK protein expression. Mol Vis. 2011;17: 210-217.

24. Kieffer ME, Efsen J. Imedeen in the treatment of photoaged skin: an efficacy and safety trial over 12 months. J Eur Acad Dermatol Venereol. 1998;11(2):129-136.

25. Heule F. An oral approach to the treatment of photodamaged skin: a pilot study. J Int Med Res. 1992;20(3):273-278.

26. Rietveld M, Janson D, Siamari R, Vicanova J, Andersen MT, El Ghalbzouri A. Marine-derived nutrient improves epidermal and dermal structure and prolongs the life span of reconstructed human skin equivalents. $J$ Cosmet Dermatol. 2012;11(3): 213-222. 
27. Costa A. Hidratação cutânea [Cutaneous moisturizing]. Rev Bras Med. 2009;66:15-21. Portuguese.

28. Costa A, Pires MC, Gonçalves HS, Gontijo B, Bechelli L. Estudo clínico observacional de eficácia e segurança do uso de extratos de Imperata cylindrica e de Triticum vulgare [Surveillance clinical trial for efficacy and safety uses of extracts of Imperata cylindrica and Triticum vulgare...]. Rev Bras Med. 2009;66:249-253. Portuguese.
29. Darvin M, Patzelt A, Gehse S, et al. Cutaneous concentration of lycopene correlates significantly with the roughness of the skin. Eur J Pharm Biopharm. 2008;69(3):943-947.

30. Addor FA, Aoki V. Skin barrier in atopic dermatitis. An Bras Dermatol. 2010;85(2):184-194.

\section{Publish your work in this journal}

Clinical, Cosmetic and Investigational Dermatology is an international, peer-reviewed, open access, online journal that focuses on the latest clinical and experimental research in all aspects of skin disease and cosmetic interventions. All areas of dermatology will be covered; contributions will be welcomed from all clinicians and basic science researchers globally. This journal is indexed on CAS

The manuscript management system is completely online and includes a very quick and fair peer-review system, which is all easy to use. Visit http://www.dovepress.com/testimonials.php to read real quotes from published authors.

Submit your manuscript here: http://www.dovepress.com/clinical-cosmetic-and-investigational-dermatology-journal 